\title{
Erratum to: Small sample properties of a ridge regression estimator when there exist omitted variables
}

\section{Ryo Uemukai}

Published online: 12 November 2011

(C) Springer-Verlag 2011

\section{Erratum to: Stat Papers (2011) 52:953-969 \\ DOI 10.1007/s00362-009-0303-z}

The condition, "where $\varepsilon_{i}$ is distributed as $N(0,1)$ ", in page 954 , line 30 \& page 956 , line 11 was incorrectly published.

The correct version is given here:

"where $\varepsilon_{i}$ is distributed as $N\left(0, \sigma^{2}\right)$ ".

The online version of the original article can be found under doi:10.1007/s00362-009-0303-z. 